\title{
Assessing Perceptual Video Quality in WIMAX NETWORKS
}

\author{
Antonia Boadi \\ Department of Electrical Engineering, University of Southern California, Los Angeles, Ca \\ and \\ Department of Physics, California State University Dominguez Hills, Carson, Ca
}

\begin{abstract}
This paper presents an approach for assessing the perceptual quality of wireless video networking applications transmitted via WiMAX, the Worldwide Interoperability for Microwave Access air interface standard. The Video Quality Model developed by Information Administration's Video Quality Expert Group is used to benchmark perceptual video quality.
\end{abstract}

\section{KEYWORDS}

Mobile Networks, WiMAX, Mobile Computing, Wireless Video Networking

\section{INTRODUCTION}

The ever-evolving nature of the telecommunications industry has fostered a climate in which system designers must respond to market trends years before business strategies or product specifications have been clearly articulated. Sound systems engineering practice requires the definition of clear specification of requirements whose correctness can be validated [6].

The front-end of the design process is dominated by potential end-users and other non-technical stakeholders who may have difficulty translating subjective goals into quantifiable performance requirements. These end users may articulate their need for a product or application in natural language. An example of such a need could be expressed as simply as "I would be willing to subscribe to an on-demand video service that provides a clear, picture when I am powerwalking in an urban setting". The fulfillment of this use case requires that network performance, video perceptual quality, receiver velocity and transmission environment be mapped to a model that simulates the scenario of interest.

System designers are concerned with modeling the behavior of mobile channels [4, 17]; the proper parameterization of these models will allow them to estimate the performance of the network in a variety of scenarios $[11,12,14,15]$. As an example, consider the above scenario in which the transmitter is stationery. The system engineer would aim to develop a resilient system capable of reliably delivering a video product to a pedestrian walking at the rate of 4 miles per hour. A properly developed model would be used to benchmark the performance of candidate designs $[1,9,10,12,16]$. 
The system-level requirement consists of several components including: velocity, transmission environment, application type, bandwidth constraints and quality-of-service (QoS). The use of reference models that approximate the Doppler power spectral density is critical to the proper estimation of system performance.

This work proposes an adaptive FEC protocol that supports the reliable delivery of compressed video streams. The design philosophy employed in this study represents a shift from the use of traditional network-centric design requirements to a more comprehensive approach that utilizes both traditional and perceptual quality metrics.

\section{RELATED WORKS}

[15] presents an overview of WiMAX along with a discussion of the underlying technologies, Architecture , Physical and MAC Layers. [12] discusses the challenges associated with satisfying reliability, quality and latency requirements of video applications transmitted over wireless networks. [14] focuses on WiMAX admission control strategies required to satisfy Quality-ofService (QoS) requirements. [16] identifies inter-layer parameters that improve video quality as utilized in unicast applications; it uses signal-to-noise-ratio (SNR) as the primary performance metric.This work presents one of the contributions described in greater detail in the author's doctoral dissertation [2].

\section{Methodology}

The methodology proposed in this paper allows system designers to perform trade studies involving the performance of candidate designs in various wireless network implementation environments. The system-level requirements must be mapped to standardized wireless model parameterizations. Reference video clips are input to the wireless channel simulator that includes error resilience mechanisms. The quality of the resultant video clip is compared to the quality of the uncorrupted clip. The collected data are used to benchmark the performance of a constellation of candidate designs.

WiMAX is used as our case study because of its flexibility in supporting a myriad of transmission environments. WiMAX networks can be implemented in theme parks, university networks, rural areas, military battlefields, as well as for distance education and entertainment applications (Pizzi, Molinaro, \& Araniti, 2015) (Seyedzadegan \& Othman, 2013) (Sgardoni, Halls, Bokhari, Bull, \& Nix, 2011) [19]. WiMAX service classes include interactive gaming, VoIP, videoconferencing, streaming media, web browsing, instant messaging and store and forward networking [18,19]. Table 1 presents the models recommended to simulate WiMAX transmission environments [7].

WiMAX provides quality of service (QoS) based on the Service Level Agreement (SLA) between the service provider and the end user [6,7].The WiMAX business model provides the flexibility to provide different SLA's to different subscribers or even to different users within the same Subscriber Station (SS). Channel State Information (CSI) is communicated by the user terminal to the base station scheduler via a Channel Quality Indicator (CQI) $[18,19]$. 


\section{Channel Modeling}

The performance of wireless communication networks is difficult to predict because the electromagnetic waves that represent a transmitted video application do not reach the receiver's antenna via a direct path. The waves may be reflected off buildings or scattered by trees or other terrain features. This results in the decomposition of the original wave into several partial-waves, each of which may provide a positive or negative contribution to the strength of the original signal, a phenomenon known as the multipath effect.

The phase relations of the partial waves determine whether they decrease or increase the strength of the received signal. Because of this, the strength of the received signal is a function of the receiver's position; in the case of a mobile receiver, signal strength is also a function of time. Receiver motion results in a shift in frequency, referred to as the Doppler shift. The arrival direction of the partial waves result in different Doppler shifts; the cumulative sum of the scattered and reflected components is a continuous spectrum of Doppler frequencies, referred to as the Doppler power spectral density. The power spectral density (PSD), of a random process captures the frequency-domain properties of the underlying process [5].

Tables 1and 2 describe the parameters that quantify the multipath fading channel are presented and related to field measurements. The signal is decomposed into 4-6 paths, referred to as taps [7]. The paths are further parameterized by the arrival delay relative to the first path and the average power. The model consists of two channels, designed $A$ and $B$. Field experiments indicate that channel is in each state a projected proportion of the time. Table 3 identifies the root mean square (RMS) and percentage of time that the simulated network conforms to the parameterization of each state. Although parameterizations have been provided for six models, the WiMAX Forum recommends that only the Pedestrian Channel A and Vehicular Model B parameterizations be used for performance modeling [7].

Table 1. Parameterization for Pedestrian Test Environment [7]

\begin{tabular}{|c|c|c|c|c|c|}
\hline \multicolumn{5}{|c|}{ ITU Channel Model for Outdoor to Indoor and Pedestrian Test Environment } \\
\hline Tap & \multicolumn{2}{|c|}{ Channel A } & \multicolumn{2}{c|}{ Channel B } & $\begin{array}{c}\text { Doppler } \\
\text { spectrum }\end{array}$ \\
\hline & $\begin{array}{c}\text { Relative delay } \\
(\mathrm{ns})\end{array}$ & $\begin{array}{c}\text { Average power } \\
\text { (dB) }\end{array}$ & $\begin{array}{c}\text { Relative delay } \\
\text { (ns) }\end{array}$ & $\begin{array}{c}\text { Average power } \\
\text { (dB) }\end{array}$ & \\
\hline 1 & 0 & 0 & 0 & 0 & Classic \\
\hline 2 & 110 & -9.7 & 200 & -0.9 & Classic \\
\hline 3 & 190 & -19.2 & 800 & -4.9 & Classic \\
\hline 4 & 410 & -22.8 & 1200 & -8.0 & Classic \\
\hline 5 & - & - & 2300 & -7.8 & Classic \\
\hline 6 & - & - & 3700 & -23.9 & Classic \\
\hline
\end{tabular}


International Journal of UbiComp (IJU), Vol.7, No.4, October 2016

Table 2. Parameterization for Pedestrian Test Environment [7]

\begin{tabular}{|c|c|c|c|c|c|}
\hline \multicolumn{5}{|c|}{ ITU Channel Model for Vehicular Test Environment } \\
\hline Tap & \multicolumn{2}{|c|}{ Channel A } & \multicolumn{2}{c|}{ Channel B } & Doppler spectrum \\
\hline & $\begin{array}{c}\text { Relative delay } \\
(\mathrm{ns})\end{array}$ & $\begin{array}{c}\text { Average power } \\
(\mathrm{dB})\end{array}$ & $\begin{array}{c}\text { Relative delay } \\
(\mathrm{ns})\end{array}$ & $\begin{array}{c}\text { Average power } \\
(\mathrm{dB})\end{array}$ & \\
\hline 1 & 0 & 0.0 & 0 & -2.5 & Classic \\
\hline 2 & 310 & -1.0 & 300 & 0 & Classic \\
\hline 3 & 710 & -9.0 & 8.900 & -12.8 & Classic \\
\hline 4 & 1090 & -10.0 & 12900 & -10.0 & Classic \\
\hline 5 & 1730 & -15.0 & 17100 & -25.2 & Classic \\
\hline 6 & 2510 & -20.0 & 20000 & -16.0 & Classic \\
\hline
\end{tabular}

Table 3. Recommended Values for ITU Channel Root Mean Square [7]

\begin{tabular}{|l|c|c|c|c|}
\hline \multirow{2}{*}{ Percentage Occurrence and Associated RMS Delay Spread for ITU Channel Models } \\
\hline \multirow{2}{*}{ Test environment } & \multicolumn{2}{|c|}{ Channel A } & \multicolumn{2}{c|}{ Channel B } \\
\cline { 2 - 5 } & r.m.s. (ns) & $P(\%)$ & r.m.s. (ns) & $P(\%)$ \\
\hline Indoor office & 35 & 50 & 100 & 45 \\
\hline Outdoor to indoor and pedestrian & 45 & 40 & 750 & 55 \\
\hline Vehicular - high antenna & 370 & 40 & 4000 & \\
\hline
\end{tabular}

\section{Assessment of Perceptual Video Quality}

This experiment investigated the performance of the WiMAX code configuration corresponding to the $1 / 2$ rate $\mathrm{CTC}$ code with transmission requirements as described in the first row of Table 4 . It would not be prudent to explore all trade excursions identified in the table due to the prohibitive computational requirements associated with benchmarking performance data for video applications. The purpose of this memo is to demonstrate the methodology. 
International Journal of UbiComp (IJU), Vol.7, No.4, October 2016

Table 4. WiMAX Code Configurations

\begin{tabular}{|c|c|c|c|c|c|}
\hline \multirow[b]{2}{*}{$\begin{array}{l}\text { Modulation } \\
\text { Type }\end{array}$} & \multirow[b]{2}{*}{$\begin{array}{c}\text { Code } \\
\text { Type/Rate }\end{array}$} & \multicolumn{2}{|c|}{$5 \mathrm{MHz}$ Channel } & \multicolumn{2}{|c|}{$10 \mathrm{MHz}$ Channel } \\
\hline & & $\begin{array}{c}\text { Downlink } \\
\text { Rate } \\
\text { (Mbps) }\end{array}$ & \begin{tabular}{|l} 
Uplink \\
Rate \\
(Mbps)
\end{tabular} & $\begin{array}{c}\text { Downlink } \\
\text { Rate } \\
\text { (Mbps) }\end{array}$ & Uplink Rate (Mbps) \\
\hline \multirow{5}{*}{ QPSK } & $1 / 2$ CTC & 0.53 & 0.38 & $\overline{1.06}$ & 0.78 \\
\hline & $1 / 2$ CTC & 0.79 & 0.57 & 1.58 & 1.18 \\
\hline & $1 / 2$ CTC & 1.58 & 1.14 & 3.17 & 2.35 \\
\hline & $1 / 2$ CTC & 3.17 & 2.28 & 6.34 & $\overline{4.7}$ \\
\hline & $3 / 4 \mathrm{CTC}$ & 4.75 & 3.43 & 9.5 & 7.06 \\
\hline \multirow[t]{2}{*}{ 16-QAM } & $1 / 2$ CTC & 6.34 & 4.57 & 12.67 & 9.41 \\
\hline & $3 / 4$ CTC & 9.5 & 6.85 & 19.01 & 14.11 \\
\hline \multirow{4}{*}{ 64-QAM } & $1 / 2$ CTC & 9.5 & 6.85 & 19.01 & 14.11 \\
\hline & $2 / 3 \mathrm{CTC}$ & 12.67 & 9.14 & 25.34 & 18.82 \\
\hline & $3 / 4 \mathrm{CTC}$ & 14.26 & 10.28 & 28.51 & 21.17 \\
\hline & 5/6 CTC & 15.84 & 11.42 & 31.68 & 23.52 \\
\hline
\end{tabular}

There is no universally accepted methodology or metric for measuring perceptual video quality. This work has adopted the Video Quality Model [7] developed by the National Telecommunications and Information Administration's (NTIA) Video Quality Experts Group (VQEG). The VQEG's Video Quality Model (VQM) consists of five models, or metrics, specifically designed for articulating requirements associated with system-level performance requirements, for objectively comparing video service products and service level agreements as well as for providing a framework for optimizing network performance and preserving constrained resources. VQM consists of five metrics, or algorithms, each of which has been designed for a particular application. They are: Developer, General, Peak-Signal-to-NoiseRatio (PSNR), Television and Videoconferencing.

The Developer Metric was optimized for applications utilizing a broad range of bit rates and video quality. This algorithm includes parameters that measure video artefacts such as jerkiness, block distortion and blurriness. Like the Developer Metric, the General metric has been optimized to capture a wide range of impairments that include blurring, block distortion, unnatural motion. The General Metric has also been calibrated using mean opinion scores from several subjective tests performed over diverse video content, video delivery systems and video coding technologies.

The Peak-Signal-to-Noise Metric has been optimized to measure the perceptual impact of the effect of transmission over a wide range of bit rates and video applications. Although the VQM PSNR metric has limited accuracy and is sensitive to calibration errors, it has gained industry acceptance [7]. The Television Metric captures the same video artefacts as the General Model but has been optimized for digital television applications. Similarly, the Videoconferencing 
Metric has been optimized to model subjective quality judgments for videoconferencing systems.

\section{RESULTS}

The perceptual quality metrics were computed as described in Figure 1. Table 5 benchmarks the perceptual quality performance of the candidate code. The metrics are scored between 1 and 100; the higher the score, the less desirable the performance. Simulation of the performance of this code structure indicates that it will not deliver the desired performance. This is probably due to the error floor characteristic of convolutional turbo codes (CTC); under the most favorable conditions, they do not provide bit error performance that exceeds $10^{-8}$ [3]. Table 5 also provides root cause analysis (RCA) for each of the metrics. The RCA provides a high level description of the types of video impairments present in the corrupted video clip, as compared to the original reference clip.

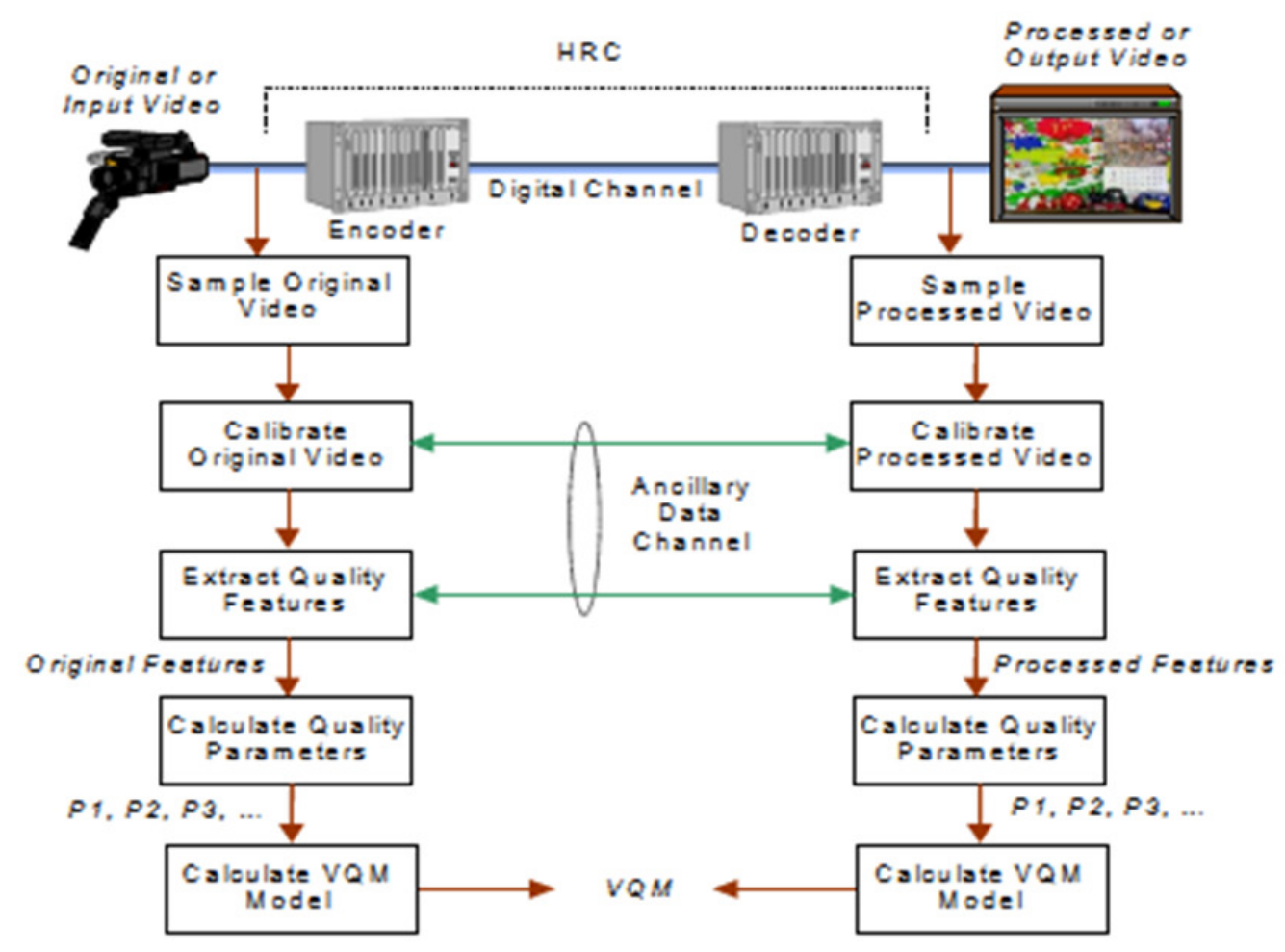

Figure 1: Steps Performed to Compute Video Quality Metrics [7] 
Table 5. Results of Video Assessment

\begin{tabular}{|c|c|c|c|c|c|}
\hline \multirow[b]{2}{*}{ BER $=10^{-7}$} & Developer & General & PSNR & Television & Videoconference \\
\hline & $\begin{array}{l}93.47 \\
\text { FAIL }\end{array}$ & \begin{tabular}{|l}
79.53 \\
FAIL \\
\end{tabular} & $\begin{array}{l}91.80 \\
\text { FAIL } \\
\end{array}$ & $\begin{array}{l}89.39 \\
\text { FAIL }\end{array}$ & $\begin{array}{l}60.44 \\
\text { FAIL }\end{array}$ \\
\hline $\begin{array}{l}\text { Description } \\
\text { of VQM } \\
\text { Root Cause } \\
\text { Analysis } \\
\text { (as described } \\
\text { in [5]) }\end{array}$ & $\begin{array}{l}\text { Blurring = } \\
55 \% \\
\text { Jerky or } \\
\text { Unnatural } \\
\text { Motion = } \\
48 \% \\
100 \%= \\
\text { perceived } \\
\text { as a } \\
\text { primary } \\
\text { artifact by } \\
\text { all viewers } \\
50 \%= \\
\text { perceived } \\
\text { as a } \\
\text { secondary } \\
\text { artifact } \\
0 \%= \\
\text { artifact not } \\
\text { perceived }\end{array}$ & $\begin{array}{l}\text { Blurring = } \\
65 \% \\
\text { Jerky or } \\
\text { Unnatural } \\
\text { Motion = } \\
8 \% \\
\text { Global } \\
\text { Noise = } \\
29 \% \\
\text { Block } \\
\text { Distortion } \\
=61 \% \\
\\
100 \%= \\
\text { perceived } \\
\text { as a } \\
\text { primary } \\
\text { artifact by } \\
\text { all viewers } \\
50 \%= \\
\text { perceived } \\
\text { as a } \\
\text { secondary } \\
\text { artifact } \\
0 \%= \\
\text { artifact not } \\
\text { perceived }\end{array}$ & N/A & $\begin{array}{l}\text { Blurring = } \\
16 \% \\
\text { Jerky or } \\
\text { Unnatural } \\
\text { Motion = } \\
22 \% \\
\text { Global } \\
\text { Noise = } \\
100 \% \\
\text { Block } \\
\text { Distortion } \\
=66 \% \\
\text { Error } \\
\text { Blocks = } \\
61 \% \\
100 \%= \\
\text { perceived } \\
\text { as a } \\
\text { primary } \\
\text { artifact by } \\
\text { all viewers } \\
50 \%= \\
\text { perceived } \\
\text { as a } \\
\text { secondary } \\
\text { artifact } \\
0 \%= \\
\text { artifact not } \\
\text { perceived }\end{array}$ & $\begin{array}{l}\text { Blurring }=37 \% \\
\text { Jerky or } \\
\text { Unnatural Motion } \\
=22 \% \\
\text { Block Distortion } \\
=33 \% \\
100 \%=\text { perceived } \\
\text { as a primary } \\
\text { artifact by all } \\
\text { viewers } \\
50 \%=\text { perceived } \\
\text { as a secondary } \\
\text { artifact } \\
0 \%=\text { artifact not } \\
\text { perceived }\end{array}$ \\
\hline
\end{tabular}

\section{ConClusions}

This paper demonstrates a methodology for estimating perceptual video quality for a variety of video applications supported by WiMAX networks. Prior to executing the simulation, the systems engineering team would draft questionnaires for the consumers as well as for the service provider. The analysis and processing of their responses would facilitate the definition of Service Level Agreements (SLA's). Simulation of the perceptual quality performance of the candidate codes could then be performed. This step suggested that the selected candidate code structure 
would be unsuitable for this application. A system designer would iteratively perform this experiment until a design or set of designs that fulfilled the system requirements has been identified.

\section{ACKNOWLEDGEMENTS}

The author would like to thank Drs. John Silvester, Behrokh Khoshnevis and Antonio Ortega for their support and guidance. The author also appreciates the helpful comments provided by the reviewers of this article.

\section{REFERENCES}

[1] Al-Jobouri, L., Fleury, M., \& Ghanbari, M. (2011). Adaptive Rateles Coding for Constant Bit Rate Data-Partitioned Wireless IPTV. Wireless Telecommunications Symposium, (pp. 1-6).

[2] Boadi, Antonia (2007), "PerFEC: Perceptually Sensitive Forward Error Control", Doctoral Dissertation, University of Southern California, Los Angeles, CA. [1]

[3] Divsalar, D. and F. Pollara (1997). Serial and Hybrid Concatenated Codes with Applications. The 1st International Symposium on Turbo Codes, Brest, France. [2]

[4] Hassanein, H., Ali, N. A., \& Taja, A.-E. M. (2012). LTE, LTE-Advanced and WiMAX: Towards IMT-Advanced Networks.

[5] Haykin, S. and M. Moher (2003), Modern Wireless Communications, Prentice Hall. [3] International Council on Systems Engineering (2015),

[6] INCOSE Systems Engineering Handbook: A Guide for System Life Cycle Processes and Activities, 4th Edition, Wiley. [4]

[7] International Telecommunications Union (1997) ITU-R Recommendation M.1225, "Guidelines for evaluation of radio transmission technologies for IMT-2000". [5]

[8] Jo, H. J., Paik, J. H., \& Lee, D. H. (2014). Efficient Privacy-Preserving Authentication in Wirelss Mobile Networks. IEEE Transactions on Mobile Computing, 1469-1481.

[9] Karimi, O., Liu, J., \& Wang, Z. (2015). Power Efficient Reource Utilization in Cellular Multimedia Multicast. Mobile Adhoc and Sensor Networks 11th Annual Conference, (pp. 134-143).

[10] Khirallah, C., Vukobratovic, D., \& Thompson, J. (2013). Bandwidth and Energy Efficiency of Video Broadcasting Services over LTE/LTE-A. Wireless Communications and Networking Conference, (pp. 1909-1914).

[11] Kong, C., Cao, X., \& Liu, M. (2013). Bayesian Video Sharing in Mobile Social Networks. Global Communications Conference (GLOBECOM), (pp. 3132-3137).

[12] Oyman, O., Foerster, J., Tcha, Y. J., \& Lee, S. C. (2010). Toward Enhanced Mobile Video Services WiMAX andLTE. IEEE Communications Magazine, 68-76.

[13] Pinson, M.H., Wolf, S.(2007) "A new standardized method for objectively measuring video quality," IEEE Transactions on Broadcasting, vol.50, no.3, pp. 312-322. [6]

[14] Pizzi, S., Molinaro, A., \& Araniti, G. (2015). Radio-Aware Resource Allocation Architecture for QoS Differentiation in WiMAX Networks. Wireles Networks.

[15] Seyedzadegan, M., \& Othman, M. (2013). IEEE 802.16: WiMAX Overview, WiMAX Architecture. International Journal of Computer Theory and Engineering.

[16] Sgardoni, V., Halls, D., Bokhari, S. M., Bull, D., \& Nix, A. (2011). Mobile WiMAX Video Quality and Transmission Efficiency. Personal Indoor and Mobile Radio Communications, (pp. 1077-1082).

[17] Wei, H.-Y., Rykowski, J., \& Dixit, S. (2013). WiFi, WiMAX and LTE Multi-Hop Mesh Networks: Basic communication Protocols and Applications.

[18] WiMAX Forum (2006). "Mobile WiMAX - Part 1: A Technical Overview and Performance Evaluation". [7]

[19] WiMAX Forum (2005). “Can WiMAX Address Your Applications?” White Paper. [8] 


\section{AUTHOR}

Dr. Boadi is a Research Fellow with the Department of Homeland Security's Center of Excellence at the University of Southern California. She is also Director of the Intelligence Community Center of Academic Excellence at California State University Dominguez Hills. She has earned a Ph.D. and Master of Science in Electrical Engineering, as well as a Master of Science in Computer Engineering, all from the University of Southern California. She completed a B.S. in Computer Science and Mathematics at California State University Dominguez Hills.

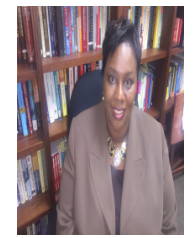

